\title{
FGFR4 Inhibitor BLU 9931
}

National Cancer Institute

\section{Source}

National Cancer Institute. FGFR4 Inhibitor BLU 9931. NCI Thesaurus. Code C162342.

An orally bioavailable, selective inhibitor of human fibroblast growth factor receptor 4 (FGFR4), with potential antineoplastic activity. Upon oral administration, FGFR4 antagonist BLU 9931 specifically and irreversibly binds to the cysteine residue at position 552 (Cys 552 ) that is within the active site of FGFR4. This blocks FGFR4 autophosphorylation and activation of receptor tyrosine kinase activity that would normally occur after binding to its ligand, fibroblast growth factor 19 (FGF19), which both inhibits FGFR4-mediated signaling and leads to an inhibition of tumor cell proliferation in FGF19- and FGFR4overexpressing cells. FGFR4, a receptor tyrosine kinase, is involved in angiogenesis and in the proliferation, differentiation, and survival of tumor cells. FGFR4 expression is associated with poor prognosis. FGF19 is overexpressed by certain tumor cell types. 